\title{
Experimental tracking and numerical mapping of novel coronavirus micro-droplet deposition through nasal inhalation in the human respiratory system
}

\author{
Hamidreza Mortazavy Beni ${ }^{1} \cdot$ Hamed mortazavi $^{1} \cdot$ Fatemeh Aghaei $^{2} \cdot$ Sanam Kamalipour $^{1}$
}

Received: 16 December 2020 / Accepted: 10 February 2021 / Published online: 1 March 2021

(c) The Author(s), under exclusive licence to Springer-Verlag GmbH, DE part of Springer Nature 2021

\begin{abstract}
It is essential to study the viral droplet's uptake in the human respiratory system to better control, prevent, and treat diseases. Micro-droplets can easily pass through ordinary respiratory masks. Therefore, the SARS-COV-2 transmit easily in conversation with a regular mask with 'silent spreaders' in the most physiological way of breathing through the nose, indoor and at rest condition. The results showed that the amount of deposited micro-droplets in the olfactory epithelium area is low. Also, due to receptors and long droplet residence time in this region, the possibility of absorption increases in the cribriform plate. This phenomenon eventually could lead to brain lesion damage and, in some cases, leads to stroke. In all inlet flow rates lower than $30 \mathrm{~L} / \mathrm{min}$ inlet boundary conditions, the average percentage of viral contamination for upper respiratory tract is always less than $50 \%$ and more than $50 \%$ for the lungs. At $6 \mathrm{~L} / \mathrm{min}$ and $15 \mathrm{~L} / \mathrm{min}$ flow rates, the average percentage of lung contamination increases to more than $87 \%$, which due to the presence of the Coronavirus receptor in the lungs, the involvement of the lungs increases significantly. This study's other achievements include the inverse relationship between droplets deposition efficiency in some parts of the upper airway, which have the most deformation in the tract. Also, the increased deformities per minute applied to the trachea and nasal cavity, which is 1.5 times more than usual, could lead to chest and head bothers.
\end{abstract}

Keywords SLA $\cdot$ CFD $\cdot$ FSI $\cdot$ DPM $\cdot$ SARS-COV-2 $\cdot$ Human respiratory system

\begin{tabular}{ll}
\multicolumn{2}{l}{ Abbreviations } \\
$x_{i} \quad$ X Cartesian coordinate \\
$x_{j} \quad$ Y Cartesian coordinate \\
$\mathrm{U}$ & Velocity $(\mathrm{m} / \mathrm{s})$ \\
$u_{f}$ & Fluid Velocity $(\mathrm{m} / \mathrm{s})$ \\
$u_{i}^{P}$ & Micro-droplet Velocity $(\mathrm{m} / \mathrm{s})$ \\
$\mathrm{P}$ & Pressure $(\mathrm{Pa})$ \\
$\mathrm{g}$ & Gravity $\left(\mathrm{m} / \mathrm{s}^{2}\right)$ \\
$\mathrm{d}$ & Particle diameter $(\mathrm{m})$ \\
$F_{x}$ & Brownian Force $(\mathrm{N})$ \\
$C_{c}$ & Cunningham correction factor \\
$S t$ & Stokes number \\
$d_{c}$ & Fluid passage path hydraulic diameter \\
$\mathrm{E}$ & Young's modulus (kpa) \\
$\mathrm{Re}$ & Reynolds number
\end{tabular}

Hamidreza Mortazavy Beni

h.mortazavy@iaua.ac.ir

1 Department of Biomedical Engineering, Arsanjan Branch, Islamic Azad University, Arsanjan, Iran

2 Department of Immunology, Shiraz University of Medical Sciences, Shiraz, Iran
$F_{i} \quad$ Body forces (N)

$D_{i} \quad$ Structural displacement (m)

$\mathrm{t}$ Time (s)

n Normal vector

\section{Greek symbols}

$\rho \quad$ Density $\left(\mathrm{kg} / \mathrm{m}^{3}\right)$

$\rho^{P} \quad$ Particle Density $\left(\mathrm{kg} / \mathrm{m}^{3}\right)$

$v \quad$ kinematic viscosity $\left(\mathrm{m}^{2} / \mathrm{s}\right)$

$\mu \quad$ dynamic viscosity (N.s $/ \mathrm{m}^{2}$ )

$\lambda$ average molecular distance for air $(\mu \mathrm{m})$

$\tau \quad$ Characteristic time (s)

$\vartheta \quad$ Poisson's ratio

$\sigma_{i j}^{f} \quad$ Fluid stress tensor

$\sigma_{i j}^{s} \quad$ Solid stress tensor

$\delta_{i j} \quad$ Kronecker delta

$\varepsilon_{i j} \quad$ Strain tensor 


\section{Introduction}

Coronavirus was first identified in 1965 (Tyrrell and Bynoe 1965). At the time, no one thought that the virus could change its genetic structure, and appear as COVID19 and could plunge the world into crisis in 2020. According to the World Health Organization, the coronavirus's death rate is ten times higher than the swine flu, which was prevalent from 2009 to 2010 . It is proposed that the virus is transmitted through direct contact and droplet outputs from the airways during cough and sneezing. With the help of high-sensitivity laser cameras, researchers have found that even in regular conversations, these droplets with diameters $\leq 10 \mu \mathrm{m}$ can float in the air for a long time (Shiu et al. 2019). An analysis of Shanley et al. (Shanley et al. 2008) in a steady flow illustrated that the deposition increases with larger particle size and flow velocity. In other study conducted by Kleinstreuer and Zhang (Kleinstreuer and Zhang 2010), a respiratory system's flows can include turbulent. Islam et al. (2020) depicted that neither Euler-Lagrange (E-L) nor Euler-Euler (E-E) methods influence the sedimentary patterns of nanoparticles with a diameter of $50 \mathrm{~nm}$ and the flow rate of 25 L/min. Ma et al. (Ma et al. 2019) exploited a standard Discrete Phase Model (DPM) method for particle deposition, and the results showed how particle deposition is affected by a narrow throat path. The reduction of the cross-sectional area of the pharynx in the epiglottis has a significant impact on the flow field in the airways, and the case of oral inhalation affects the deposition of the regional sediment. Keyhani et al. (Keyhani et al. 1995) found that the highest velocity of inhaled air alongside the nasal floor occurred under the lower turbinate in the main nasal route. Moreover, Weak airflow occurs in the middle of the airway, between the lower and middle turbinate and the septum. About $30 \%$ of the inhaled volume flow rate passes under the lower turbinate, and about $10 \%$ passes through the olfactory airway. Hörschler et al. (Hörschler et al. 2003) presented the numerical simulation of flow in a human nasal cavity model in a multi-block structural grid and compared it with experimental data. Calculations for inhalation and exhalation at rest performed with the Reynolds numbers $\operatorname{Re}=1560$ and $\operatorname{Re}=1230$, respectively, in the nostrils. Grgic et al. (Grgic et al. 2004) illustrated that aerosol deposition, caused by morphological limitations of the pharynx, glottal, and flow jets, is more common in the larynx and trachea. Also, it is found that the deposition efficiency is related to the inertia parameter. Even if the Stokes number is kept constant, the accumulation efficiency increases with the increasing Reynolds flow due to the velocity profile change. Another study showed that both total and regional deposition have substantial differences and a significant difference in intersubjectivity (Grgic et al. 2004; Jin et al. 2007; Xi and Longest 2007; Jayaraju et al. 2007; 2014). Heenan et al. (Heenan et al. 2004) showed a strong relationship between local deposition and the local fluid velocity field. The level of local deposition is strongly related to the velocity and curvature of the flow. Shi et al. (Shi et al. 2006) found that tiny particles $\leq 5$ nanometers in diameter are particularly important because they were absorbed more rapidly. Therefore, the larger particles have a higher toxicity or therapeutic effect. Xi and Longest (Xi and Longest 2008) examined the particles with $1 \mathrm{~nm}$ size up to $1 \mu \mathrm{m}$ and an inhalation flow rate of 4-30 L/min. Under these circumstances, the turbulence was visible only in the nasal valve area and the nasopharynx's posterior region. They also found that many of the main parts of the nose have a flow with small variation. Chen et al. (2012) found that secondary flow may contribute to particles' deposition in the filled airways for actual inhalation. The results obtained by Nicolaou and Zaki (Nicolaou and Zaki 2013) provide insight into how the geometry changes affect the aerosol deposition and the dispersion of the deposition data. The assessment of flow fields in different mouth and throat geometries allows us to investigate the source of the deposition dependence on Reynolds number. Shinneeb and Pollard (Shinneeb and Pollard 2012) showed that the nature of the respiratory system flow is three-dimensional and is associated with the recirculation, jet-like and sink-like form flows. It can be understood from the above research that there is very little information available on droplet deposition in the respiratory system. Therefore, employing the Fluid-Structure Interaction (FSI) method into the complex geometry of the respiratory system could generate an accurate answer. In general, drug administration with aerosol inhalers is preferable in the treatment of respiratory disorders. Yousefi et al. (Yousefi et al. 2017) experimentally investigate the transport and deposition of drug particles into a silicon lung model made by computer tomography (CT) scan; using the DPM method and computational fluid dynamics (CFD) simulation of aerosol delivery to the human lung by surface acoustic wave nebulization. They concluded that the location of particle injection could affect the drug's delivery efficiency. In addition, regardless of the injection site, they found that the ratio of drug particles penetration to the right lung was significantly higher than the left lung. Pourmehran et al. (Pourmehran et al. 2016) used the DPM method and CFD simulation for airflow and particle deposition in the presence of an external magnetic field in the human respiratory system's geometry; in which polystyrene particles (PMS40) were used as the magnetic drug carrier. During the investigation, they found a significant improvement in particle deposition in the presence of a magnetic drug targeting (MDT) in the target regions (for 
example, in the left lung). Pourmehran et al. (Pourmehran et al. 2015) simulated magnetic drug targeting through tracheal airways in the presence of a nonuniform external magnetic field using the Lagrangian magnetic particle tracking method. Considering different inlet flow rate and particle pattern, they determined that the particle deposition efficiency increases in the target region in the presence of the magnetic field. Furthermore, for the magnetic field $\leq 1$ Tesla, deposition efficiency and MDT technique are directly related to increasing particle diameter. Pourmehran et al. (Pourmehran et al. 2020) used CFD and discrete phase model to investigate the effect of aeroacoustics parameters such as frequency, amplitude and the average inlet flow rate on the efficiency of acoustically driven drug delivery (ADD) to the human maxillary sinus. Through numerous simulations, they found that the amplitude is the most important parameter influencing the delivery of acoustic drug to the maxillary sinus in the amplitude of oscillation of the air plug in the ostium. Pourmehran et al. (Pourmehran et al. 2020) also investigated the effect of geometric parameters on acoustic-driven drug delivery to maxillary sinuses in the resonance frequency of the nose-sinus model. They performed the acoustic model both experimentally and computationally along with theoretical analysis to determine the ideal nasal sinus model's resonance frequency. The results showed that there is a significant coincidence between the experimental and CFD modeling. Pourmehran et al. (2020) used CFD and DPM to investigate the effect of drug diameter and particle density on drug delivery efficiency to the maxillary sinus in the aeroacoustics technique. The results demonstrated that the increase of diameter and particles' density in the presence of an acoustic field reduces the acoustics stokes number, which has a negative effect on drug delivery efficiency.

Micro-droplets are a subcategory of aerosols; nevertheless, there is no investigation of viral effects performed about droplets $\leq 10 \mu \mathrm{m}$ diameter. Even in vitro studies have not been performed to determine these droplets' exact deposition location in the upper human respiratory system. These small micro-droplets can pass through ordinary respirator masks and can contaminate people if the permitted distance is not observed. However, it should be noted that ordinary masks are more useful for droplets $>>10$ $\mu \mathrm{m}$ (Leung et al. 2020). As mentioned in the literature review, avoiding the real model of the respiratory system can immensely affect particle deposition location. Real geometry is fundamental in modeling, and computational methods based on actual body performance can affect the results. Unlike previous studies in which the motion of particles examined by CFD; the FSI boundary condition is used in this study. Also, the human's physiological conditions behave like FSI boundary condition.

\section{Materials and method}

\subsection{Computational model}

The model used in this study is related to a 30-year-old healthy man in previous study, in which the agreement of the model with reality has been demonstrated in terms of the turbulent characteristics (2019) and behavior of the elastic wall boundary condition (2019) of the respiratory system. This model could accurately predict the results of deposition and the effects of the coronavirus droplet in the human upper respiratory system by injecting viral droplet through the oral inhalation (Mortazavi 2020). To construct the airway model, CT scans of a 30-year-old male without any problems in his respiratory system were used in this study. While the person was in a supine status, the scans were obtained by TABA imaging center. Under the professional supervision, the boundary between the airway mucosa and air in the upper respiratory tract was defined in each CT scans' slices. The three-dimensional (3D) model of the upper airway was extracted using CT technology. The 3D model includes nasal cavity, pharynx, larynx, and trachea. The boundaries were imported to GAMBIT, a CFD preprocessor software, in which the boundaries connect to each other to create a smooth surface and shape the volume. An unstructured triangular hybrid volume mesh was generated inside the airway passage. Details of reconstruction of geometry and meshing of this model have been presented in Mortazavy et al. study (2019), and it is not mentioned here again. Fig. 1 shows the meshed geometry and segmentation of the computational model. Due to the nasal area's importance and its complex geometry, this area is divided into three essential segments: superior turbinate, middle turbinate, and inferior turbinate. This study employs a computational model extracted from a CT imaging of a male subject. Also, the FSI modeling includes variations in viral droplet's size and density at low velocity. All the data obtained with air inhaled through the nose. The DPM was used to inject droplets into the model. One-way fluid-particle coupling was used in computational modeling. Also, by producing a physical model with stereolithography (SLA) and injecting stained droplets into it, the numerical results' accuracy was ensured.

\subsection{Governing equations}

Air was considered as a viscous and incompressible fluid. The governing equations for the quasi-steady turbulent flow in the human respiratory system are the Navier-Stokes and continuity equations. These equations include:

$\frac{\partial U_{i}}{\partial x_{i}}=0$ 


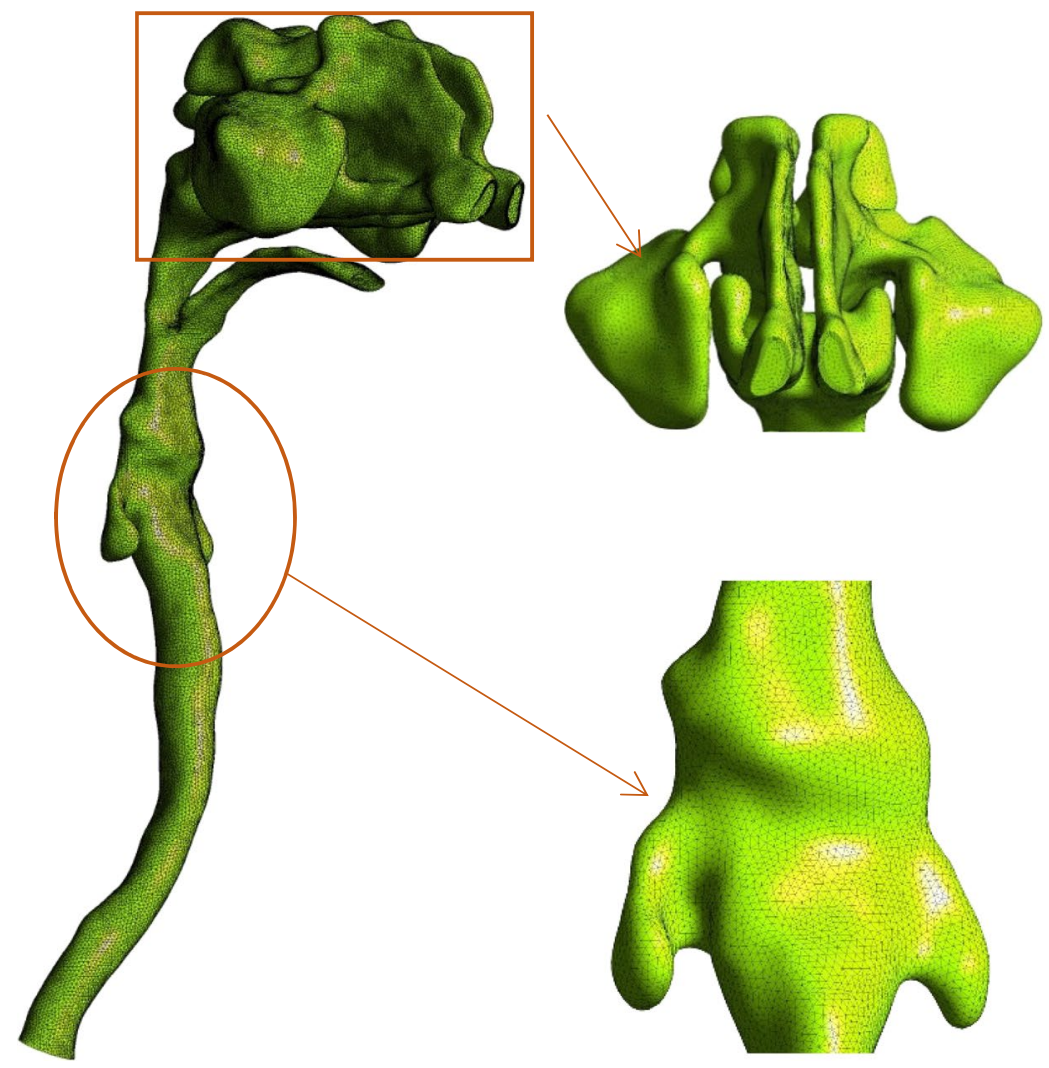

(I)

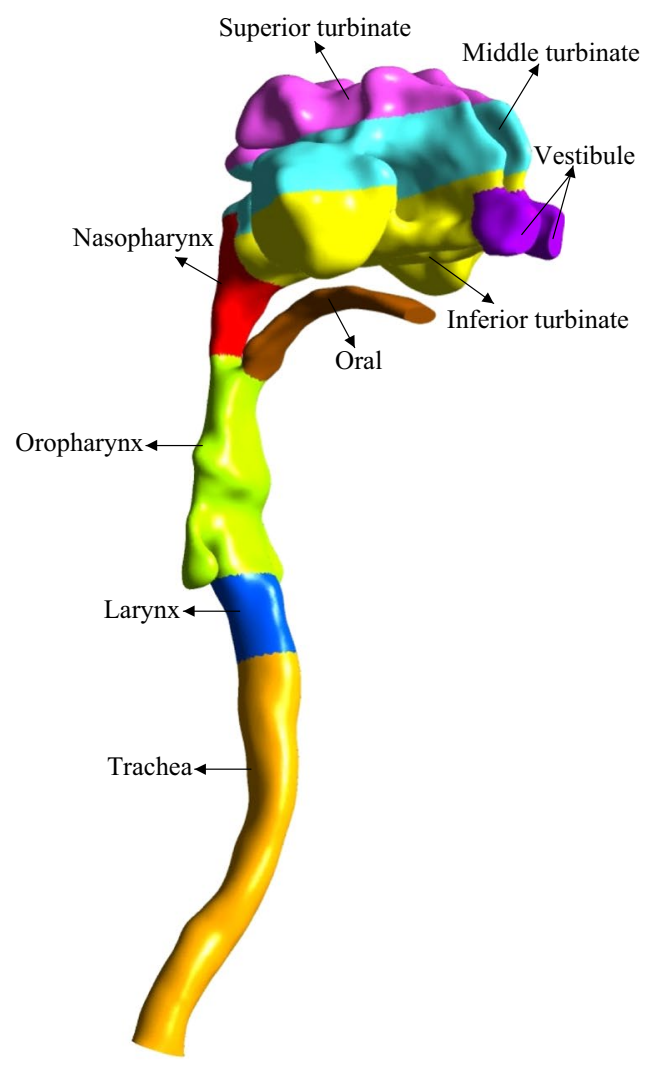

(II)

Fig. 1 Segmentation and meshing of the present computational model. a Mesh generation. b Anatomical segmentation of the 3D model

$U_{i} \frac{\partial U_{j}}{\partial x_{i}}=-\frac{1}{\rho} \frac{\partial P}{\partial x_{i}}+\frac{\partial}{\partial x_{i}}\left[v\left(\frac{\partial U_{i}}{\partial x_{j}}+\frac{\partial U_{j}}{\partial x_{i}}\right)-\overline{U_{i}^{\prime} U_{j}^{\prime}}\right]+G_{i}$

In these equations, the parameters $U, \rho, P, v$ and $G_{i}$ for airfluid represent speed, density, pressure, kinematic viscosity, and gravity term, respectively. Also, i and j represent Cartesian coordinates. Based on Kleinstreuer and Zhang (Kleinstreuer and Zhang 2010), the E-L method was selected to better investigate the micro-droplet particle movement along with fluid. The equation of motion for the micro-droplet is as follows:

$\frac{d u_{i}^{P}}{d t}=\left(\frac{18 \mu}{\rho^{P} d^{2} C_{c}}\right)\left(U_{i}-u_{i}^{P}\right)+g_{i}+F_{x}$

Also, $\mu, \rho^{P}, d, g_{i}$ and $F_{x}$ are viscosity, particle density, particle diameter, gravity term, and Brownian Force, respectively. Furthermore, in this equation, $\frac{d x_{i}}{d t}=u_{i}^{P}$ Also, $C_{c}$ is the Cunningham correction factor, which is equal to (2006)

$C_{c}=1+\frac{2 \lambda}{d}\left(1.257+0.4 e^{-\frac{1.1 d}{2 \lambda}}\right)$
In this equation, $\lambda$ is the average molecular distance for air and was assumed to be $0.065 \mu \mathrm{m}$. The Stokes number was used to calculate the ratio of the droplet's characteristic time per the characteristic time scale of the flow, which is defined as follows (2006).

$S t^{P}=\frac{\tau u_{f}}{d_{c}}$

In which $\tau$ is the characteristic time, $u_{f}$ is the velocity of the fluid, and $d_{c}$ is the hydraulic diameter of the tract through which the fluid passes. By putting the value of residence time, the following equation is obtained (2006)

$S t^{P}=\frac{\rho^{P} d^{2} u_{f}}{18 \mu d_{c}}$

The fluid and solid domains were coupled through the stress tensor. The Cauchy stress tensor in an isotropic Newtonian fluid field was (2019)

$\sigma_{i j}^{f}=-p \delta_{i j}+2 \mu\left(\varepsilon_{i j}-\frac{1}{3} \varepsilon_{k k} \delta_{i j}\right)$ 
where $\sigma_{i j}^{f}$ is the fluid stress tensor, $\delta_{i j}$ is Kronecker delta, and $\varepsilon_{i j}$ is the rate of the strain tensor which is given by

$\varepsilon_{i j}=\frac{1}{2}\left(\frac{\partial u_{i}}{\partial x_{j}}+\frac{\partial u_{j}}{\partial x_{i}}\right)$

In the structural field, the governing equation of linear elasticity are as follows:

$\frac{\partial \sigma_{i j}^{s}}{\partial x_{j}}+F_{i}=\rho \frac{\partial^{2} D_{i}}{\partial t^{2}}$

Where $F_{i}$ is the body forces, $D_{i}$ is the structural displacement, $\sigma_{i j}^{s}$ is the solid stress tensor, $\mathrm{t}$ is time. The Cauchy stress tensor in the structural field is defined as follows:

$\sigma_{i j}^{f}=\frac{E v}{(1+v)(1-2 v)} \varepsilon_{k k} \delta_{i j}+\frac{E}{(1+v)} \varepsilon_{i j}$

where $\mathrm{E}$ is Young's modulus, $v$ is the Poisson's ratio, $\varepsilon_{i j}$ is the strain tensor Eq. (4). The coupling conditions of fluid and solid domain at the FSI boundary are the matching of the fluid velocity and structural displacement

$u_{i}=\frac{\partial D_{i}}{\partial t}$

and the force equilibrium across the FSI interface $\sigma_{i j}^{f} n=-\sigma_{i j}^{s} n$

where $\mathrm{n}$ is the normal vector outward of the FSI interface. The walls of the airway were considered elastic walls. Also, it is assumed that the droplets were absorbed in the first encounter with the wall. More details on the governing equations of FSI are mentioned in the Mortazavy et al. study (2019) and are not repeated here for the sake of brevity. In the present model, based on Shanley et al. (Shanley et al. 2008), the fixed boundary conditions, nostrils, and end of the trachea (carina zone) are where the flow rate enters and exits, respectively, and the wall boundary condition is applied to the mouth's entrance.

The geometry was entered in ANSYS 2020 R1. Fluent software converts and solves the governing equations into algebraic equations by the finite volume method. In this study, the second-order upwind scheme was used for the momentum equation discretization, and the SIMPLE algorithm was used to couple the pressure and velocity equations. The k-epsilon turbulence model is a subcategory of the RANS group, which has been shown to have viable results in the use of DPM in the study of deposition mapping in the human respiratory system (Ma et al. 2019). That is why this method was used in this study, and the reliability of this method was confirmed, according to Fig. 2 (see Sect. 5). In the simulation process, air entered the model at $25^{\circ} \mathrm{C}$ from

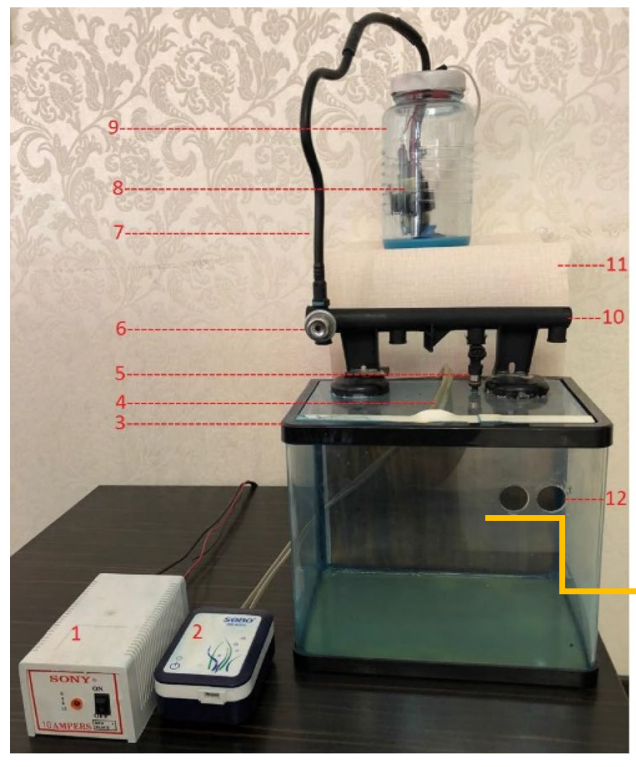

(I)
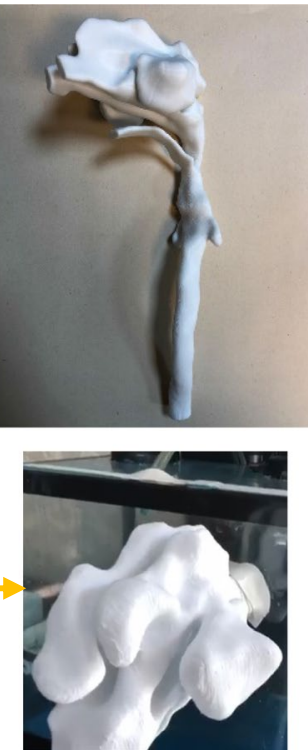

(II)

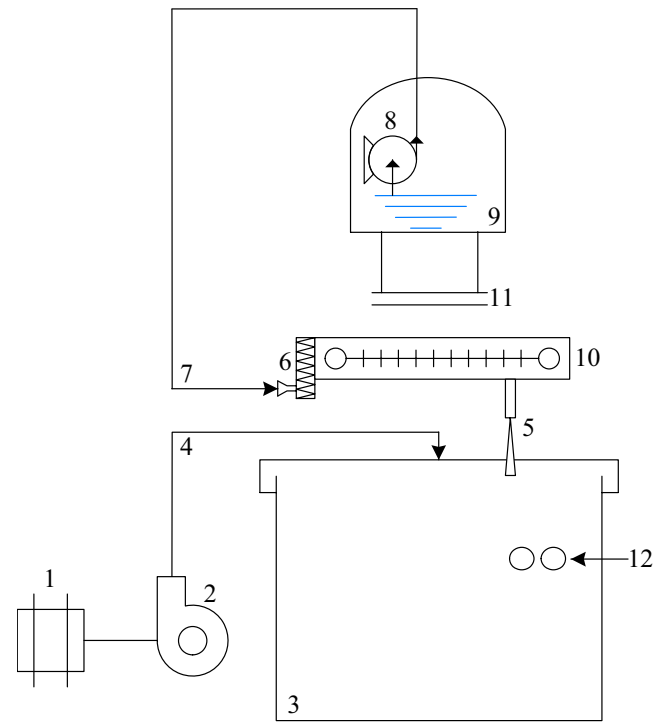

(III)
Fig. 2 Experimental setup for validating the deposition pattern. a Experimental apparatus, b 3D printing model and connecting the model to the tank, c The production schematic of the blue droplet, and its movement in the model. Views: (1): Power supply, (2): SB-4000 air pump, (3): Evacuation tank, (4): Air transfer hose, (5):
Bosch injector-EV 140280158057 (This injector produces only a 10-micron diameter droplet at a pressure of 3 bar), (6): Pressure regulator, (7): Liquid transfer tube, (8): Liquid pump, (9): Liquid tank, (10): Constant pressure rail, (11): Support base, (12): System output to the upper airway respiratory model 
the nostril, and three amount of density considered for droplets entering the model. Then, the deposition efficiency was assessed in each state. $\rho_{1}=998 \mathrm{~kg} / \mathrm{m}^{3}$ for pure water density, $\rho_{2}=1119 \mathrm{~kg} / \mathrm{m}^{3}$ equivalent to $50 \%$ water $+50 \%$ virus (average density), and $\rho_{3}=1240 \mathrm{~kg} / \mathrm{m}^{3}$ was assumed for net virus droplet, given that the COVID-19 virus belongs to the Betacoronavirus family, and the density of the Betacoronaviruses is approximately $\rho=1240 \mathrm{~kg} / \mathrm{m}^{3}$ (Decaro and Betacoronavirus $\ddagger$, in The Springer Index of Viruses, C. Tidona and G. Darai Editors. 2011). Also, the range of droplet diameter changes in normal conversation was considered from 1 to $10 \mu \mathrm{m}$ (2015). For the respiratory wall, the expansion of the Young's modulus and Poisson's ratio was considered in the range of $0.51 \mathrm{kpa} \leq \mathrm{E} \leq 100.64 \mathrm{kpa}$ and $\vartheta=0.3-0.45$, respectively (Birch and Srodon 2009).

\subsection{Physical experiment}

As can be seen in Fig 1, the airway model was built using stereolithography. Tensile tests determined the isotropic Young's modulus and Poisson's ratio of the SLA material to be 996pa and 0.327 , respectively. The droplet production circuit and its movement in the model were designed as Fig. 2 to evaluate the droplet's surface deposition pattern.
After calibrating the equipment, the blue-colored fluid is pumped into the constant pressure rail with a medium density of 1119 with 3 bar pressure toward the injector. However, before entering the injector, the liquid is stabilized again by the constant pressure rail with a 3 bar pressure so that the injector can produce $1,023 \mathrm{~cm}^{3} /$ min droplet with a diameter of 10 micrometers. The liquid is sprayed in the tank and conducted by the air pump with an airflow of $6 \mathrm{~L} /$ $\min$. Finally, $10 \mu \mathrm{m}$ droplets move to the model through the nostril. The outlet flow moved from the trachea to a tank equipped with a pressure adjustment device and a sensitive weight scale. Soft flanges on each end were used for sealing. In Fig. 3, by cutting the model and comparing the surface deposition pattern, the computational method's performance can be visually ensured. The droplet deposition pattern contour is presented at the $10 \mu \mathrm{m}$ diameters in the $6 \mathrm{~L} / \mathrm{min}$ flow rate in Fig. $3 \mathrm{k}$. As shown, the regions where the maximum deposition occurs in both the computational model and laboratory model (Fig. 3a, i) are blue. According to Fig. 3, it can be concluded that the deposition pattern in both models follows the same visually trend and compatibility with together. On the other hand, the overall deposition efficiency and escaped droplet were 14.8 and 85.2 , respectively, with less than $\% 5$ error with results achieved in the numerical model for one inlet boundary condition $(6 \mathrm{~L} / \mathrm{min}, 10-\mu \mathrm{m}$

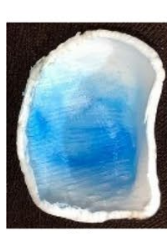

(I)
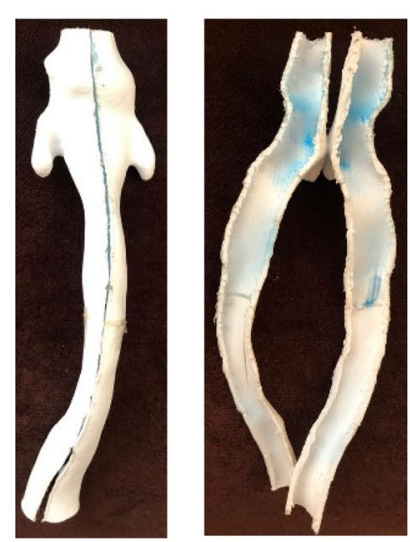

(IX)

(II)

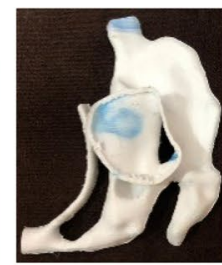

odel and comparing the surface deposition patFig. 3 Cutting the model and comparing the surface deposition pat-
tern between the experimental and numerical models for the nostril inlet in $10 \mu \mathrm{m}$ droplet at $6 \mathrm{~L} / \mathrm{min}$ flow rate. Views: a Inside of the left maxillary sinus, $\mathbf{b}$ Inlet of the left maxillary sinus, $\mathbf{c}$ main airway of the left nasal cavity, $\mathbf{d}$ main airway of the center nasal cavity (leftview), e main airway of the center nasal cavity (right-view), $\mathbf{f}$ main

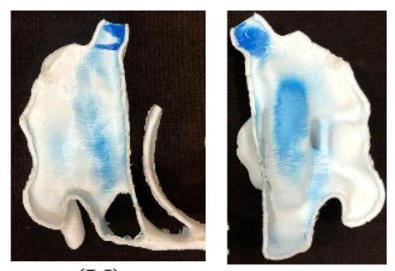

(V)

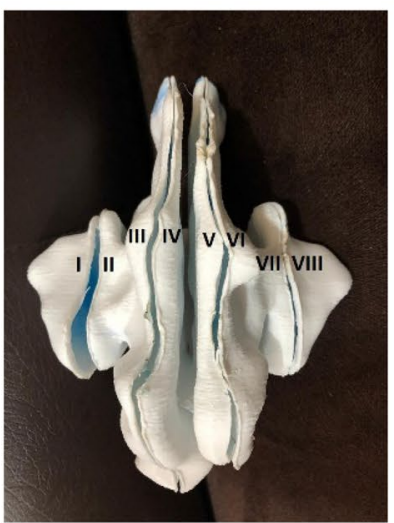

$(\mathrm{X})$

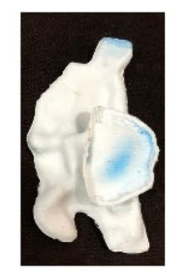

(VII)

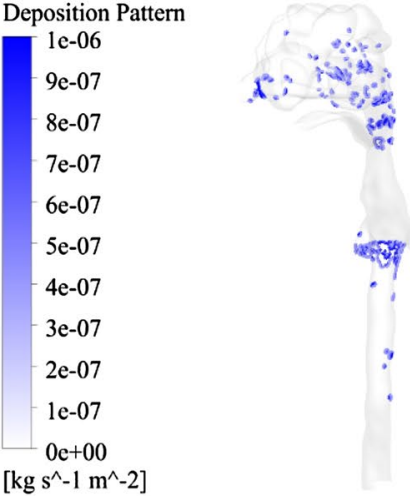

$\left[\mathrm{kg} \mathrm{s} \mathrm{s}^{\wedge}-1 \mathrm{~m}^{\wedge}-2\right]$

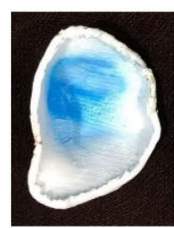

(VIII)

(XI) airway of right nasal cavity, $\mathbf{g}$ Inlet of the right maxillary sinus, $\mathbf{h}$ Inside of the right maxillary sinus, i Assembly and disassembly of the lower airway tract including oropharynx, larynx, and trachea. $\mathbf{j}$ Top view of the upper airway tract, including nasopharynx, nasal cavity, and vestibule assembled. $\mathbf{k}$ Deposition pattern in the numerical model 
droplet), (Sect. 4, Table 1). Also, Fig. (VI) and Fig. (IX) depicts that the lowest droplet deposition occurs in the right olfactory zone and trachea, where the most deformation take place according to Fig. 9 (see Sect. 3).

\section{Results}

In this study, airflow enters from the nostrils with the closed mouth; then, the airflow and droplet parameters and wall deformation analysis were investigated. Three flow rates of 6,15 , and $30 \mathrm{~L} / \mathrm{min}$ were entered into the model along with the droplet diameter change, and based on this, the upper respiratory system's performance was evaluated from different aspects. Meanwhile, the flow rate of $6 \mathrm{~L} / \mathrm{min}$, and the $5 \mu \mathrm{m}$ droplet are the basis for comparisons. It should be noted that during normal breathing, a man in a state of rest breathes about $500 \mathrm{~cm}^{3}$ of air per inhalation, which is

Table 1 Summarizes the deposition and Escape efficiency percentage

\begin{tabular}{llrccc}
\hline Flow Rate & Size $\mu \mathrm{m}$ & Deposited & Escaped & $\begin{array}{l}\text { Average } \\
\text { deposition }\end{array}$ & $\begin{array}{l}\text { Average } \\
\text { Escape }\end{array}$ \\
\hline $6 \mathrm{~L} / \mathrm{min}$ & 1 & 5.07 & 94.93 & 9.49 & 90.51 \\
& 5 & 7.93 & 92.07 & & \\
& 10 & 15.47 & 84.53 & & \\
$15 \mathrm{~L} / \mathrm{min}$ & 1 & 9.62 & 90.38 & 12.39 & 87.61 \\
& 5 & 9.88 & 90.12 & & \\
& 10 & 17.68 & 82.32 & & \\
$30 \mathrm{~L} / \mathrm{min}$ & 1 & 13.52 & 86.48 & 43.43 & 56.57 \\
& 5 & 31.58 & 68.42 & & \\
& 10 & 85.19 & 14.81 & & \\
\hline
\end{tabular}

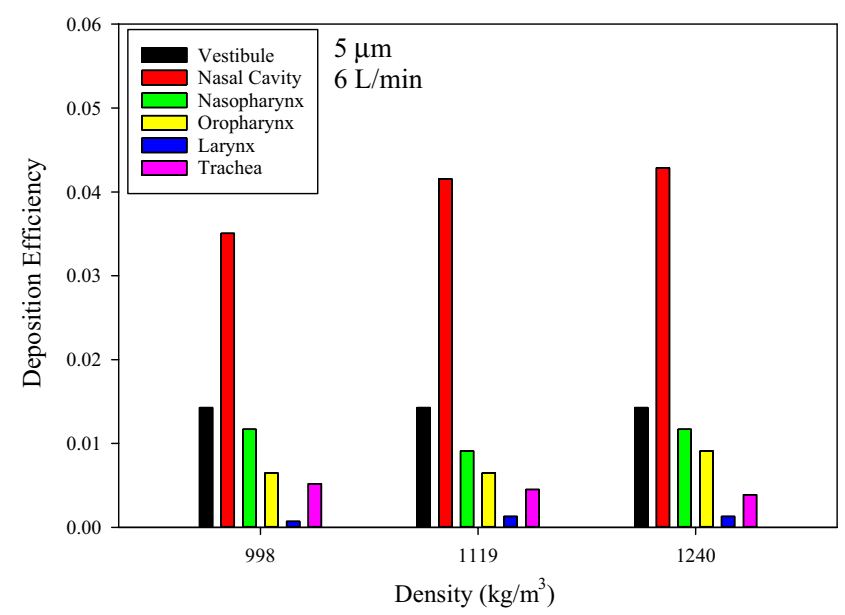

(I) the same as the tidal volume at rest (1992). This number is precisely concordant with the model presented in this study after spirometry testing during patient's health condition in the database (2019). Therefore, the model's inlet flow rate was considered $6 \mathrm{~L} / \mathrm{min}$ in indoor and at rest mode.

According to Fig. 4a, the highest droplet deposition occurred in the nasal cavity at rest position. On the other hand, by the growth of the droplet density, the deposition's amount increases in the nasal cavity. The deposition efficiency is always smaller than $5 \%$, and after the nasal cavity, the highest droplet deposition occurs in the vestibule, nasopharynx, oropharynx, trachea, and larynx, respectively. The nasal deposition rate is more than two times greater than in other parts of the respiratory tract. So, Fig. $4 \mathrm{~b}$ has been considered for investigation of droplet deposition level in three essential parts of the nasal cavity; it is clear that the deposition's efficiency is always smaller than $2.5 \%$. As seen, the highest droplet deposition is in the inferior turbinate, and the lowest deposition is in the superior turbinate (olfactory zone). Also, with the growth of droplet density, the droplet deposition increases in the olfactory region.

If we evaluate the droplet residence time parameter in the respiratory system, similar to contour with the transparent face wall in Fig. 5, it can be seen that the most residence time of the particles is in the nasal part, especially in the olfactory and maxillary sinus area. Due to the geometric conditions in these areas, the flow recirculates, and the droplet gets stuck. After these two regions, the recirculating turbulence flow and residence value in the oropharynx zone should be mentioned, which, although it is not to the extent of the nasal part, but is relatively noticeable throughout the breathing path from the nasopharynx to the trachea.

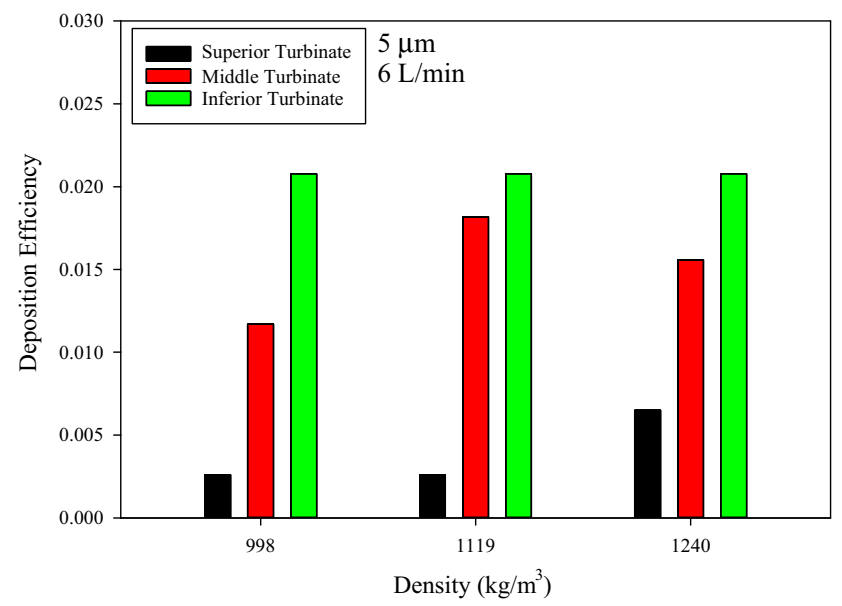

(II)

Fig. 4 Droplet deposition in the upper respiratory tract at $5 \mu \mathrm{m}$, and $6 \mathrm{~L} / \mathrm{min}$ condition for the inhalation from the nostril entrance with a closed mouth. a Entire upper airway. b Only a nasal cavity. 


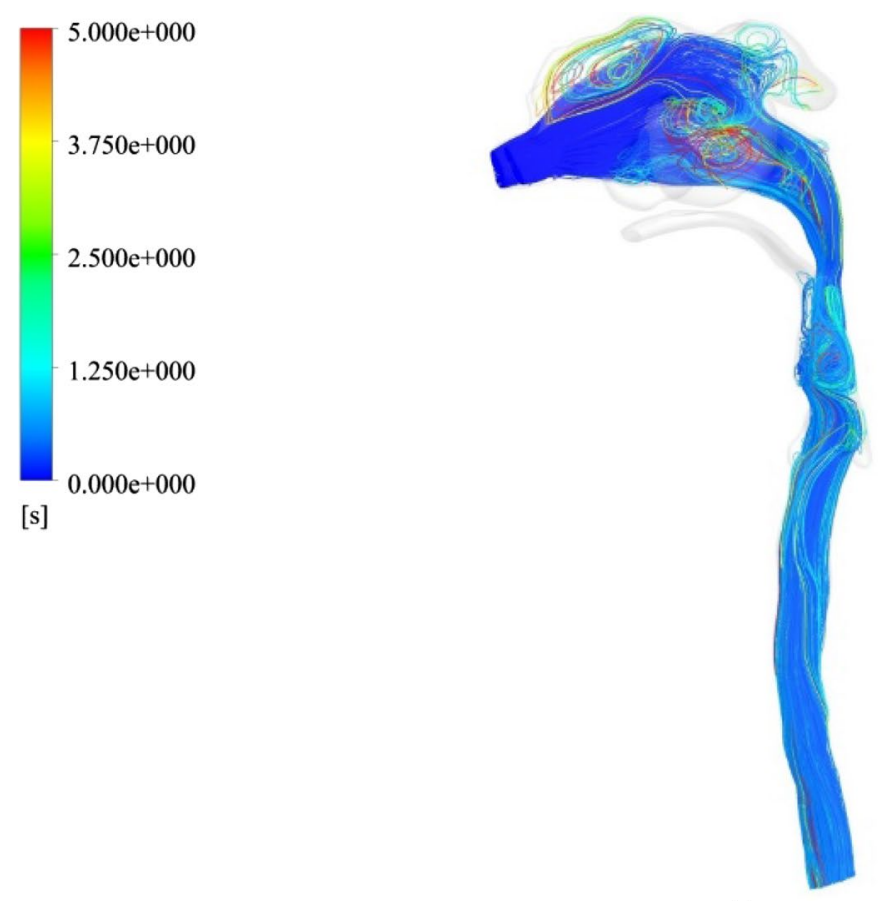

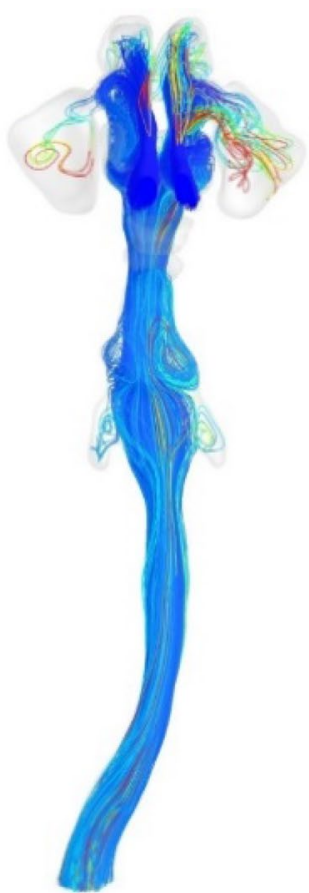

(I)

(II)

Fig. 5 Droplet residence contour with average density at $5 \mu \mathrm{m}$ diameter and $6 \mathrm{~L} / \mathrm{min}$. a Droplet residence time tracking in the sagittal plane. b Droplet residence time tracking in the coronal plane

Droplet deposition is a superficial phenomenon. Fig. 6 shown the concentration of droplets in the volume. It is evident in this figure that the droplet concentration in the nasal cavity, carina zone, and the oropharynx is higher than in other areas. In other words, in some parts of the respiratory system where geometric curves are more complex, the droplets can be trapped, and subsequently, the concentration increased.

In order to obtain a more significant relationship between the density, the diameter, and the flow rate changes in the whole scope of the droplet study, as shown in Fig. 7, the deposition efficiency curve was plotted according to the Stokes number. Based on Fig. 7a, with the growth of Stokes number, the rate of deposition efficiency increases exponentially in different parts of the respiratory system, so that the rate Stokes number changes are lower than one, and the rate of deposition does not exceed $40 \%$. The highest and the lowest reports in the amount of deposition are in the oropharynx and the trachea, respectively. Now, according to Fig. 7b, if the deposition changes per Stokes number considered in the nasal cavity, it could be perceived that the highest droplet deposition occurs in the inferior turbinate, which is smaller than $10 \%$ and the lowest deposition is obtained in the superior turbinate.

Fig. 8a shows the effect of changes in flow rate and droplet diameter in the respiratory system's deposition.
In general, with the growth of diameter or flow rate, the amount of deposition efficiency increases. The effect of flow rate elevation on the droplet deposition increased significantly, by the droplet diameter increase. To clarify, in $10 \mu \mathrm{m}$ droplet, when the flow rate doubles from 15 to 30 , the droplet deposition escalates almost five times, and the deposition efficiency increases to $85 \%$. Fig. 8 b illustrates the same trend only in the nasal cavity, with the difference that deposition efficiency does not exceed 5\%. As seen in this curve, the most significant deposition is often in the inferior turbinate and the least in the superior turbinate.

As seen in Fig. 9, the deformation contour in the respiratory system is extracted based on inhalation through the nose. In this figure, the most deformation is related to the trachea at the carina zone. Also, the most deformed part of the nasal cavity is the olfactory zone. In other words, in places where deformation increases, the deposition rate depicts a significant decrease (see Fig. 7). The maximum deformation rate at flow rates of 15 and $30 \mathrm{~L} / \mathrm{min}$ is 5 and 21 times, higher than the flow rate of $6 \mathrm{~L} / \mathrm{min}$, respectively. Additionally, the maximum increase percentage in deformation is several times greater than the flow rate increase. Also, Fig. 9d compares the deformed geometry versus the original geometry. As shown in this figure, most changes from the deformed geometry (colorful contour) to the original geometry (blue contour) occur in the trachea. 


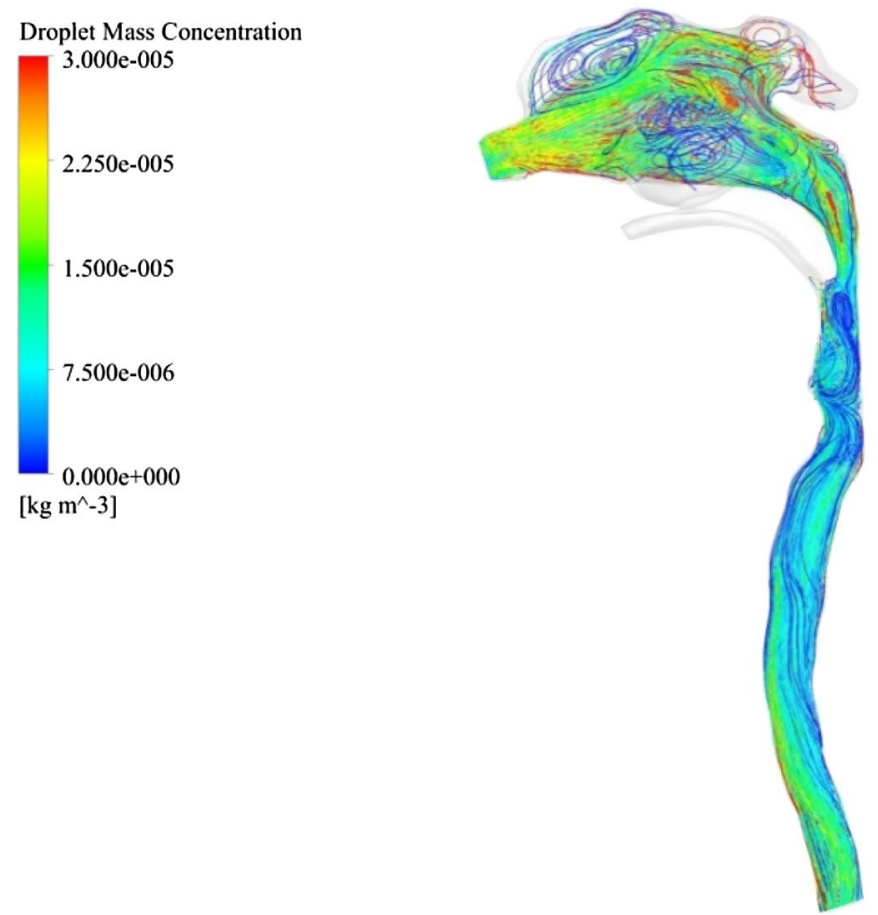

(I)

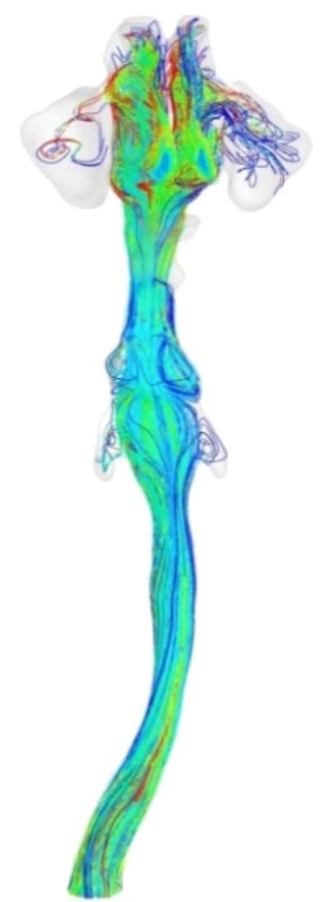

(II)

Fig. 6 Concentration droplet contour at average density in $6 \mathrm{~L} / \mathrm{min}$ flow rate, and $5 \mu \mathrm{m}$ droplet. a Sagittal plane concentration on the respiratory tract. b Coronal plane concentration on the respiratory tract

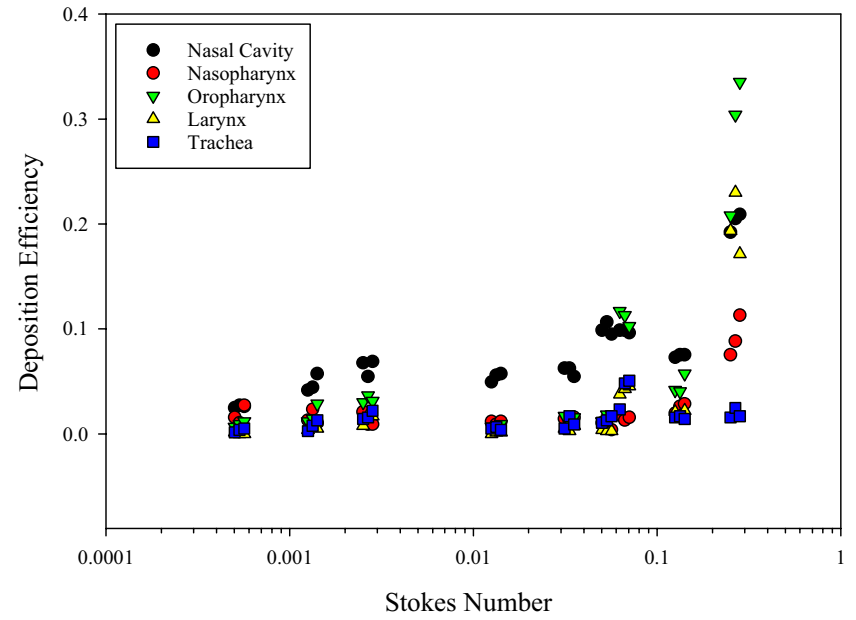

(I)

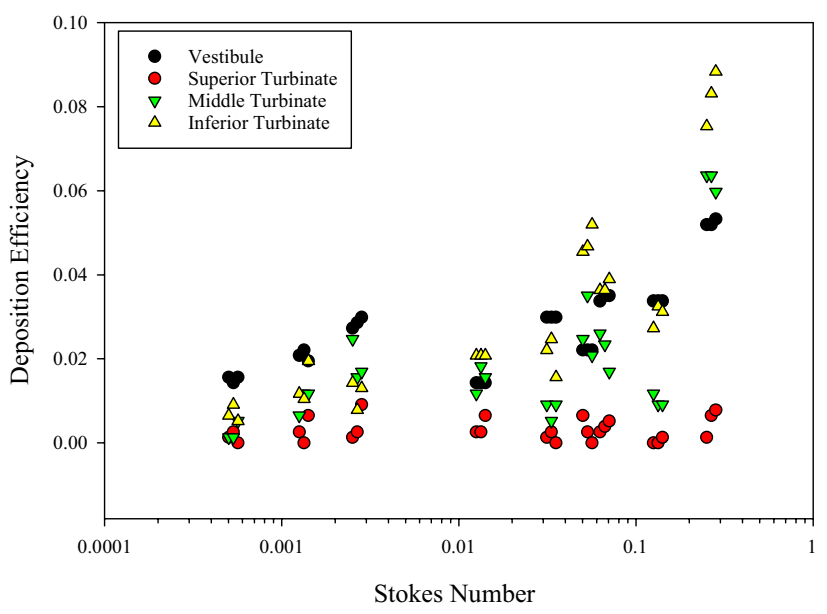

(II)

Fig. 7 Deposition efficiency change according to the Stokes number. a In the whole respiratory airway. $\mathbf{b}$ In the different zone of the nasal cavity

\section{Discussion}

At the time of inhalation, the constant number of the droplets was injected into the respiratory system from the nose's entrance. Airflow enters from the nostrils with the closed mouth as a limitation of the study. The DPM method and the FSI boundary condition in a real model were applied to achieve a more accurate answer. Finally, a model with reliable output responses developed, which is more consistent with the physiological behavior of the human body and the experimental model. Undoubtedly, tracking the viral droplet's effects in the respiratory tract can help cope with, and treat the disease. When, 


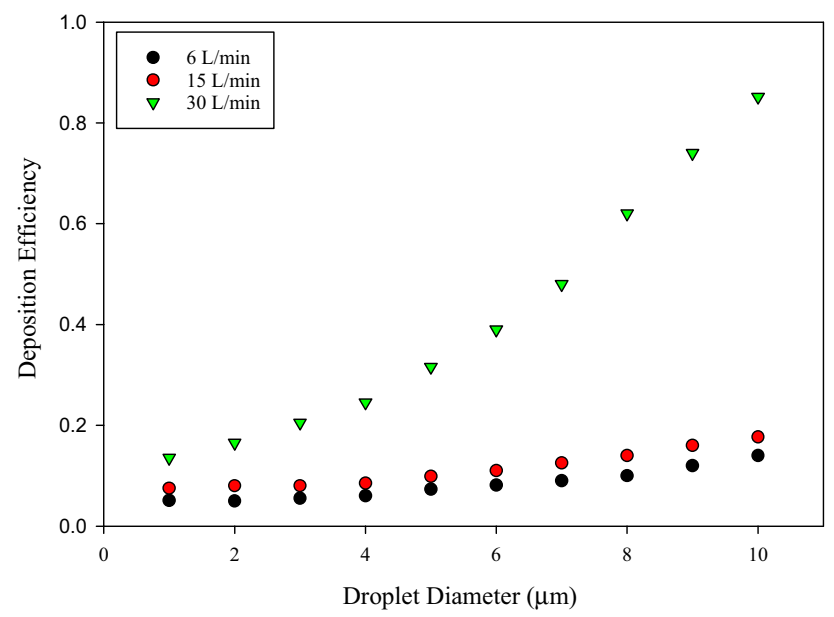

(I)

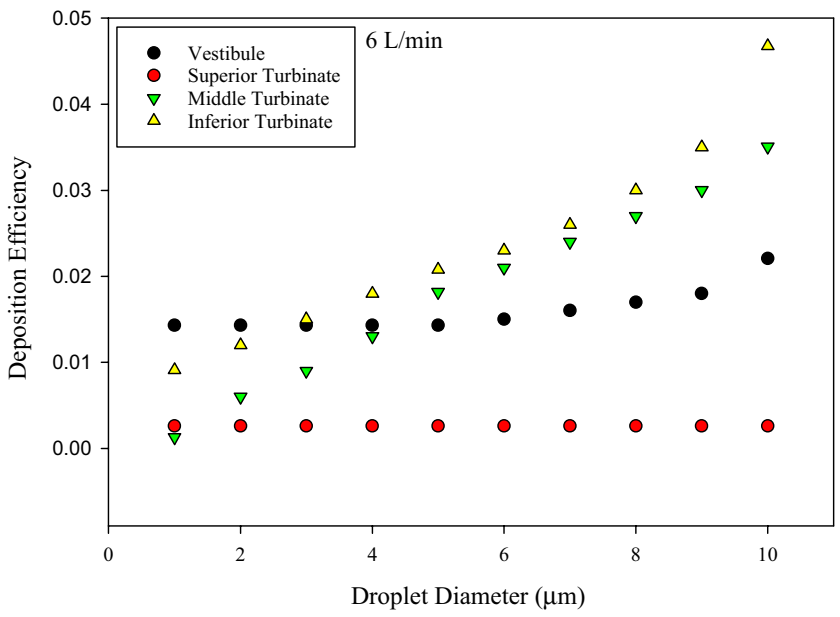

(II)

Fig. 8 Effect of diameter on deposition efficiency with average droplet density and $5 \mu \mathrm{m}$ diameter. a In the entire inhalation path at the different flow rates. $\mathbf{b}$ In the different nasal cavity zone at a flow rate of $6 \mathrm{~L} / \mathrm{min}$.

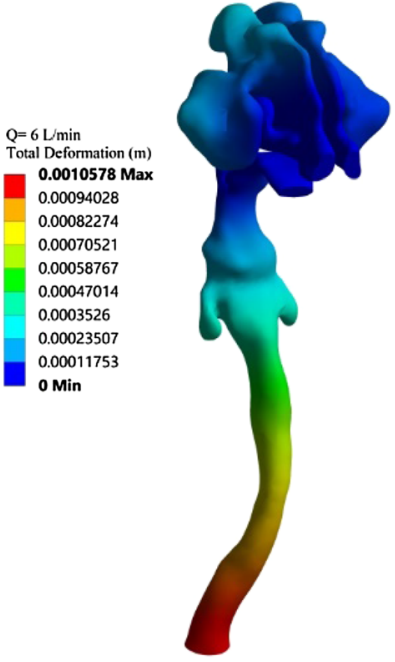

(I)

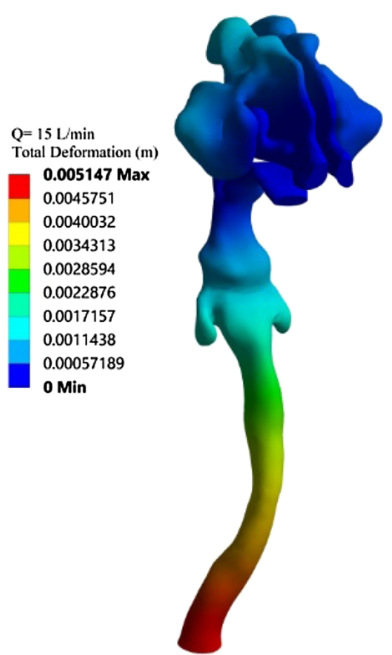

(II)

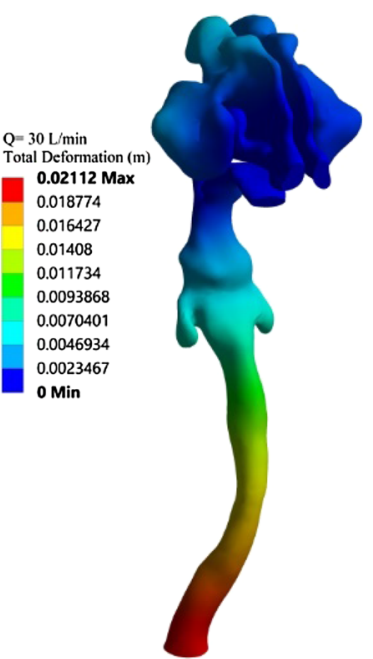

(III)

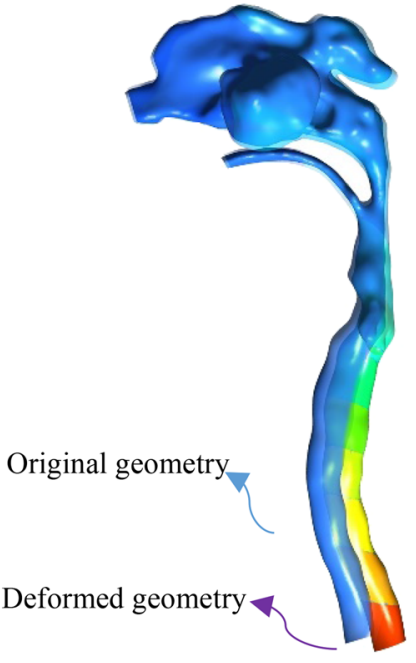

(IV)
Fig. 9 Deformity contour at average density for different flow rates entered the nostrils with the closed mouth at the $5 \mu \mathrm{m}$ droplet. a Inlet flow $6 \mathrm{~L} / \mathrm{min}$. b Inlet flow $15 \mathrm{~L} / \mathrm{min}$. c Inlet flow $30 \mathrm{~L} / \mathrm{min}$. d Com-

an infected person exhales, a significant number of viral micro-droplets are produced, which can be suspended in the air and even move longer distances; this phenomenon makes the disease transmission faster. Therefore, the primary mode of comparisons for the flow rate was considered $6 \mathrm{~L} / \mathrm{min}$ which indicates the person's breathing rate at the rest position. In an indoor construction, the risk of virus transmission through micro-droplets increases with improper ventilation. If a person starts moderate physical activity in such construction, depending on the level of paring the deformed geometry versus the original geometry at inlet flow $30 \mathrm{~L} / \mathrm{min}$ in the Sagittal plane. The blue contour shows the original geometry without deformation. activity, the results of the flow rate will be more applicable to $15 \mathrm{~L} / \mathrm{min}$ and $30 \mathrm{~L} / \mathrm{min}$.

With nostrils inhalation, the most deposition occurs in the nasal cavity at the resting inhalation (Fig. 4). The residence time that occurs in the superior turbinate is very high (Fig. 5), with a relatively high concentration (Fig. 6). The coronavirus receptors are activated in the olfactory area (Baig et al. 2020), where the olfactory nerve is a part of the odor system, and it has a short path in the central nervous system to the brain. Viral droplet deposition in the superior 
turbinate and the presence of the virus receptors in the olfactory epithelium could lead to the neurologic manifestations in more than $30 \%$ of COVID-19 patients (2019); as loss of sense of smell and taste were observed in the studied subject. Because of the viral droplet absorption in the superior turbinate, this region is a dangerous zone, and the stroke probability after the viral droplet absorption could be increased, as shown in Fig. 10.

However, evaluating the deposition efficiency in terms of Stokes number can provide a better attitude of the viral droplet's effects at all densities and diameters of the droplet at different inhalation flow rates. It can be understood (Fig. 7) with certainty that by increasing the Stokes number, the deposition efficiency increases in all boundary conditions of the viral droplet and flow rate. Such parameters including the droplet's diameter can play a decisive role in viral droplet deposition, due to the nonlinear relationship between the Stokes number and the droplet's diameter and the fluid flow rate regarding the individual's level of physical activity. As the droplet's diameter or the flow rate always increases, the deposition efficiency increases (Fig.8). Table 1 summarizes the deposition and escapes efficiency percentage with flow rate and viral droplet diameter changes in the upper respiratory tract. The last two columns of this table present the average deposition percentage in the upper respiratory airway, and the average escaped viral droplets reached bronchi. It is clear that in all inlet boundary conditions, the average percentage of viral contamination is less than $50 \%$ for upper respiratory tract and more than $50 \%$ for the lung. At $6 \mathrm{~L} / \mathrm{min}$ and $15 \mathrm{~L} / \mathrm{min}$ flow rates, the average percentage of lung contamination increases to more than $87 \%$, which due to the activation of the Coronavirus receptor in the lungs (Baig et al. 2020), the involvement of the lungs increases significantly.
Figure 11, based on Table 1, shows a better view of the contamination possibility of the upper airway or lung. According to Fig. 11a, by increasing the flow rate and droplet diameter, the process of upper airway contamination increases so that for $10 \mu \mathrm{m}$ droplet and $30 \mathrm{~L} / \mathrm{min}$ airflow, the upper airway contamination is significantly increased. On the other hand, it is evident that by increasing the flow rate and droplet diameter, lung contamination decreases (Fig. 11b). From a general view and comparison of Fig. 11a, $\mathrm{b}$, it can be seen that the possibility of lung contamination in nasal inhalation is relatively high.

Droplet deposition pattern contour is presented at the 1,5, and $10 \mu \mathrm{m}$ droplet diameters in the $30 \mathrm{~L} / \mathrm{min}$ flow rate in Fig. 12, in which for better illustration, only droplet deposition areas were demonstrated. The most contamination zones with viral droplet after its entry through the nostrils are in sequence vestibule, inferior turbinate, nasopharynx, oropharynx, larynx, and trachea arch. The droplet deposition increased in these zones by droplet diameter growth, and therefore the less viral droplet reached the lungs.

A healthy 30-year-old man inhaled 12 times per minute in a healthy condition. The number of ordinary breaths per minute for a healthy person older than 14 years is 12 to 20 times per minute (Lu et al. 2020). However, after being infected with the COVID-19 virus, the person's respiration rate increased to 20 times per minute, which was also seen in Chen et al. study (Chen et al. 2020). In other words, the patient's breathing rate increases at least $\frac{20}{12}=1.67$ times per minute. Therefore, concerning the increase in the number of inhalation per minute, the number of respiratory deformations and subsequent cyclic stresses in the trachea wall and olfactory zone (Fig. 9), also increase per minute compared to the healthy state. So, it comes with no surprise that, according to the World Health Organization reports, one of the

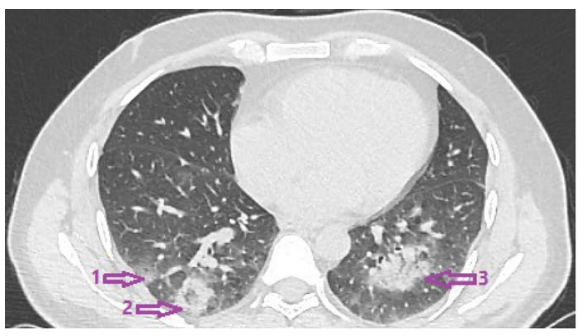

(I) Present patient with COVID-19 disease, prepared from Taba-Parto Shiraz radiology center. 1: opacities, 2: nodule shape, 3: opacities consolidation.

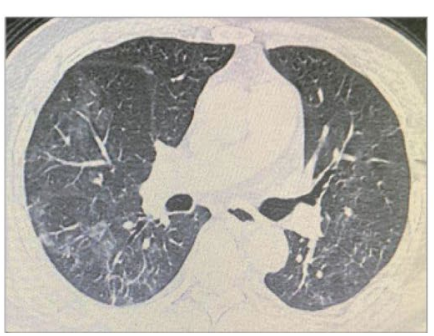

(II) Chest CT of the patient with the COVID-19 disease [37].

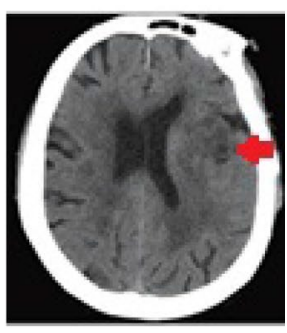

(c) Lesion brain CT after stroke identified with a red arrow [37].
Fig. 10 CT images of the chest and brain of COVID-19 male patients. a lesions to the patient's lung have been identified in this study with a purple arrow. b CT images of the lung of a COVID-19 patient one day after stroke in another study (2019). c CT brain photograph of the patient one day after a stroke (2019). a Present patient with COVID-19 disease, prepared from Taba-Parto Shiraz radiology center. 1: opacities, 2: nodule shape, 3: opacities consolidation. b Chest CT of the patient with the COVID-19 disease (2019). c Lesion brain CT after stroke identified with a red arrow (2019) 


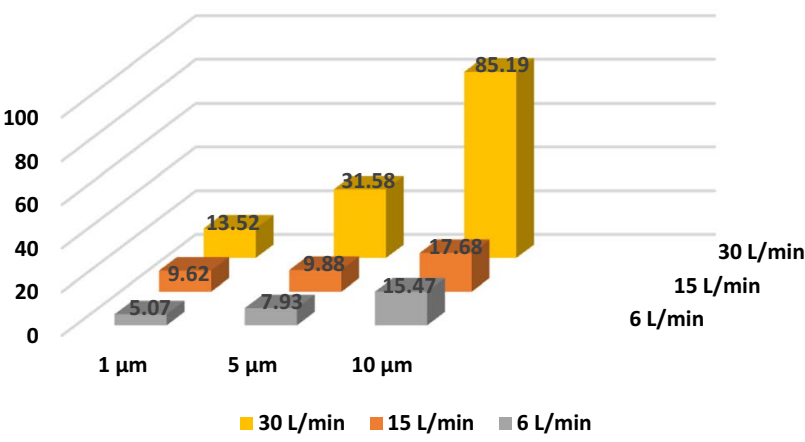

(I)

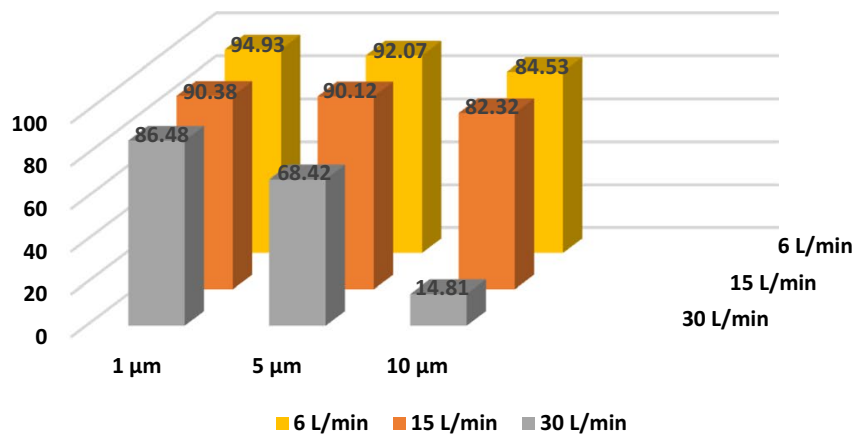

(II)

Fig. 11 Viral contamination probability percentage in nasal inhalation for the droplet with 1, 5, and $10 \mu \mathrm{m}$ diameters at 6,15, and $30 \mathrm{~L} / \mathrm{min}$ airflow. a Viral upper airway contamination probability percentage. b Viral lung contamination probability percentage

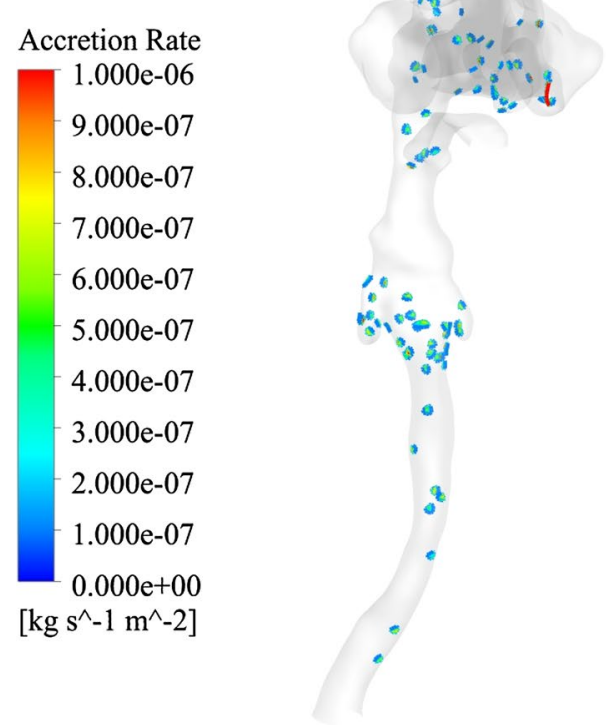

(I)

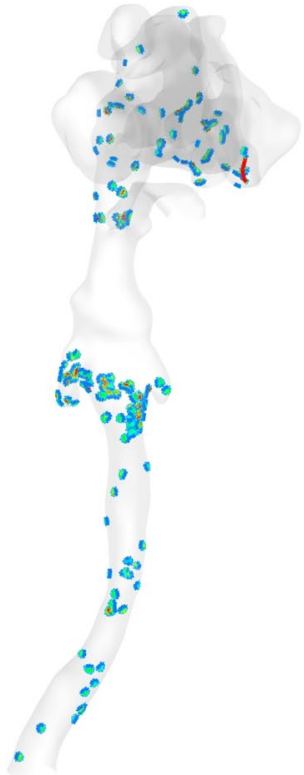

(II)

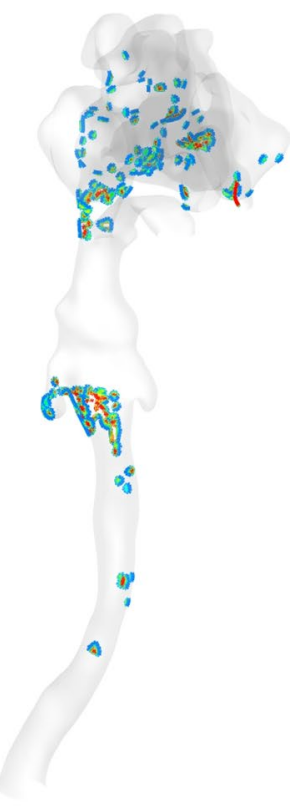

(III)

Fig. 12 Droplet deposition with 1, 5, and $10 \mu \mathrm{m}$ droplet diameters at 30L/min airflow. a Nose inlet $1 \mu \mathrm{m}$ droplet. b Nose inlet $5 \mu \mathrm{m}$ droplet $\mathbf{c}$ Nose inlet $10 \mu \mathrm{m}$ droplet

symptoms of the disease is feeling pressure in the chest and head. It is noticeable that aspiration of 6 liters air per minute is equal to the amount of blood volume that the heart pumps per minute. Due to COVID-19 infection, some parts of the lungs are distorted. Therefore, the lungs have to compensate for this decrease by increasing the number of breaths per minute.

Another essential point in this FSI model is that the most deformation can be seen in the carina zone and the olfactory zone, respectively; while the least droplet deposition occurs in these areas. The CT images confirmed that the droplet deposition at the carina angle is smaller than the tracheal wall. Whereas in contrast, the result of the unrealistic models is vice versa (Islam 2020). Hence, the FSI method implementation in the analysis of droplet deposition in the upper human respiratory system is of great necessity to detect viral-contaminated areas accurately. Anatomical dead space is represented by the volume of air that fills the conducting zone of respiration. These segments of the respiratory tract include the upper airways, trachea, bronchi, and terminal bronchioles. This volume of the air is returned to the lungs after an exhalation during the next inhales (2018; 2019). Therefore, if the anatomical dead space is contaminated with the virus, the droplet deposition residence time will increase significantly. This phenomenon can be effective in more viral droplet's deposition in anatomical dead space. 
Inhalation through the mouth or nose can be very effective in the results of viral droplet deposition in the human upper airway (Mortazavi 2020). Also, a valid model is one that has successfully passed through the validation process (Cobelli and Carson 2019). These instructions have been carefully observed in the laboratory model presented in this research.

\section{Conclusion}

Because of the SARS-COV-2's importance and its effect on the respiratory system, finding solutions to control and deal with this type of virus is a great necessity. Therefore, the physical properties of the SARS-COV-2, such as density, viral droplets diameter, and airflow were chosen to investigate the droplets behavior and deposition pattern in nasal inhalation. Finally, suggestions to prevent the effect of these viral droplets were provided.

This study is an attempt to model the deposition of viral droplets inhaled by the nose into the upper human respiratory tract. The actual model presented demonstrates that the sense of smell of the studied person was disturbed due to the accumulation of viral droplets in the nasal cavity, and its high residence time in the superior turbinate. By increasing the flow rate and droplet diameter, the process of upper airway contamination increases so that for $10 \mu \mathrm{m}$ droplet and $30 \mathrm{~L} / \mathrm{min}$ airflow, the upper airway contamination is significantly increased. On the other hand, by increasing the flow rate and droplet diameter, lung contamination decreases. Also, the droplet deposition efficiency has a reverse relationship with tract wall deformation. However, we believe that the model should be applied for different persons, and an atlas of data could be obtained from different cases. That may help the medical system to have more data about the viral deposition pattern.

Acknowledgements We thank the Taba-Parto Shiraz radiology center for assistance with the 3D CT scan. All procedures performed in studies involving human participants were in accordance with the institutional and/or national research committee's ethical standards and with the 1964 Helsinki declaration and its later amendments or comparable ethical standards. The authors of the manuscript declare that they have no conflict of interest. Any organization or university did not fund the research

\section{Declaration}

Conflict of interest The authors of the manuscript hereby declare that they have no conflict of interests. The research was not funded by any organization or university

\section{References}

ANSYS-Fluent (2006). Fluent 6.3 Users Guide, Lebanon, USA
Baig AM, Khaleeq A, Ali U, Syeda H (2020) Evidence of the COVID-19 Virus targeting the CNS: tissue distribution, Hostvirus interaction, and proposed neurotropic mechanisms. ACS Chem Neurosci 11(7):995-998

Birch MJ, Srodon PD (2009) Biomechanical properties of the human soft palate. Cleft Palate Craniofac J 46(3):268-74

Cameron, J.R., J.G. Skofronick, and R.M. Grant (1992) Medical Physics: physics of the body: Medical Physics Publishing Corporation

Chen T, Wu D, Chen H, Yan W, Yang D, Chen G, Ma K, Xu D, Yu H, Wang H, Wang T, Guo W, Chen J, Ding C, Zhang X, Huang J, Han M, Li S, Luo X, Zhao J, Ning Q (2020) Clinical characteristics of 113 deceased patients with coronavirus disease 2019: retrospective study. BMJ 368:m1091

ChenZhongSun ShengZhou XwBBX (2012) Study on gas/solid flow in an obstructed pulmonary airway with transient flow based on CFD-DPM approach. Powder Technol 217:252-260

Cobelli C, Carson E (2019) Introduction to modeling in physiology and medicine. Academic Press, USA

Decaro N (2011) Betacoronavirusł. In: Tidona C, Darai G (eds) The springer index of viruses. Springer, New York, pp 385-401

Grgic B, Finlay WH, Burnell PKP, Heenan AF (2004) In vitro intersubject and intrasubject deposition measurements in realistic mouth-throat geometries. J Aerosol Sci 35(8):1025-1040

Grgic B, Finlay WH, Heenan AF (2004) Regional aerosol deposition and flow measurements in an idealized mouth and throat. $\mathrm{J}$ Aerosol Sci 35(1):21-32

Heenan AF, Finlay WH, Grgic B, Pollard A, Burnell PK (2004) An investigation of the relationship between the flow field and regional deposition in realistic extra-thoracic airways. J Aerosol Sci 35(8):1013-1023

Hörschler I, Meinke M, Schröder W (2003) Numerical simulation of the flow field in a model of the nasal cavity. Comput Fluids 32:39-45

Intagliata S, Rizzo A, Gossman WG. (2019) StatPearls [Internet]. StatPearls Publishing; Treasure Island (FL): May 15, Physiology, Lung Dead Space

Islam MS, Paul G, Ong HX, Young PM, Gu YT, Saha SC (2020) A review of respiratory anatomical development, air flow characterization and particle deposition. Int J Environ Res Public Health 17(2):380-396

Islam, M.S., Saha, S.C., Gemci, T. et al. (2019) Euler-Lagrange Prediction of Diesel-Exhaust Polydisperse Particle Transport and Deposition in Lung: Anatomy and Turbulence Effects. Sci Rep 9, 12423

Jayaraju ST, Brouns M, Verbanck S, Lacor C (2007) Fluid flow and particle deposition analysis in a realistic extrathoracic airway model using unstructured grids. J Aerosol Sci 38(5):494-508

Jin HH, Fan JR, Zeng MJ, Cen KF (2007) Large eddy simulation of inhaled particle deposition within the human upper respiratory tract. J Aerosol Sci 38(3):257-268

Keyhani K, Scherer PW, Mozell MM (1995) Numerical simulation of airflow in the human nasal cavity. J Biomech Eng 117(4):429-41

Kleinstreuer C, Zhang Z (2010) Airflow and particle transport in the human respiratory system. Annu Rev Fluid Mech 42(1):301-334

Leung NHL, Chu DKW, Shiu EYC et al (2020) Respiratory virus shedding in exhaled breath and efficacy of face masks. Nat Med 26(5):676-680

Li D, Xu Q, Liu Y, Libao Y, Jun J (2014) Numerical simulation of particles deposition in a human upper airway. Adv Mech Eng. https://doi.org/10.1155/2014/207938

Lu X, Zhang L, Du H, Zhang J, Li YY, Qu J, Zhang W, Wang Y, Bao S, Li Y, Wu C, Liu H, Liu D, Shao J, Peng X, Yang Y, Liu Z, Xiang Y, Zhang F, Silva RM, Pinkerton KE, Shen K, Xiao H, Xu S, Wong GWK (2020) SARS-CoV-2 infection in children. N Engl J Med 382(17):1663-1665 
Ma B, Kourmatzis A, Zhao B, Yang R, Chan H, Salehi F, Cheng SH (2019) Potential effects of lingual fats on airway flow dynamics and particle deposition. Aerosol Sci Technol 54(3):321-331

Mao L, Jin H, Wang M, Hu Y, Chen S, He Q, Chang J, Hong C, Zhou Y, Wang D, Miao X, Li Y, Hu B. "Neurologic Manifestations of Hospitalized Patients With Coronavirus Disease 2019 in Wuhan, China". JAMA Neurol, 2020.

Mortazavi Hamed (2020) Hamidreza Mortazavy Beni, Fatemeh Aghaei, Hossein Sajadian, SARS-CoV-2 droplet deposition path and its effects on the human upperairway in the oral inhalation. Comput Methods Prog Biomed. https://doi.org/10.1016/j. cmpb.2020.105843

Mortazavy Beni H, Hassani K, Khorramymehr S (2019) Study of the sneezing effects on the real human upper airway using fluid-structure interaction method". J Braz Soc Mech Sci Eng. https://doi. org/10.1007/s40430-019-1677-z

Mortazavy Beni, H., K. Hassani, and S. Khorramymehr. "In silico investigation of sneezing in a full real human upper airway using computational fluid dynamics method". Comput Meth Prog Biomed, 2019. 177: p. 203-209.

Nicolaou L, Zaki TA (2013) Direct numerical simulations of flow in realistic mouth-throat geometries. J Aerosol Sci 57:71-87

Pourmehran O, Arjomandi M, Cazzolato B et al (2020) The impact of geometrical parameters on acoustically driven drug delivery to maxillary sinuses. Biomech Model Mechanobiol 19:557-575

Pourmehran Oveis, Cazzolato Benjamin, Tian Zhao, Arjomandi Maziar (2020) Acoustically-driven drug delivery to maxillary sinuses: Aero-acoustic analysis. Eur J Pharma Sci 51:105398

Pourmehran O, Gorji TB, Gorji-Bandpy M (2016) Magnetic drug targeting through a realistic model of human tracheobronchial airways using computational fluid and particle dynamics. Biomech Model Mechanobiol 15:1355-1374

Pourmehran O, Rahimi-Gorji M, Gorji-Bandpy M, Gorji TB (2015) Simulation of magnetic drug targeting through tracheobronchial airways in the presence of an external non-uniform magnetic field using Lagrangian magnetic particle tracking. J Magn Magn Mater 393:380-393

Pourmehran, O., Arjomandi, M., Cazzolato, B., and Tian, Z. (2020) Effect of particle diameter and density on acoustic drug delivery to maxillary sinus - a sensitivity study. 22nd australasian fluid mechanics conference AFMC2020, Brisbane, Australia, 7-10 December: The University of Queensland

Quinn M, Rizzo A. (2018) StatPearls [Internet]. StatPearls Publishing; Treasure Island (FL): Dec 6, Anatomy, Anatomic Dead Space

Shanley KT, Zamankhan P, Ahmadi G, Hopke PK, Cheng YS (2008) Numerical simulations investigating the regional and overall deposition efficiency of the human nasal cavity. Inhal Toxicol 20(12):1093-100

Shi H, Kleinstreuer C, Zhang Z (2006) Laminar airflow and nanoparticle or vapor deposition in a human nasal cavity model. J Biomech Eng 128(5):697-706

Shinneeb AM, Pollard A (2012) Investigation of the flow physics in the human pharynx/larynx region. Exp Fluids 53(4):989-1003

Shiu EYC, Leung NHL, Cowling BJ (2019) Controversy around airborne versus droplet transmission of respiratory viruses: implication for infection prevention. Curr Opin Infect Dis 32(4):372-379

Tyrrell DAJ, Bynoe ML (1965) Cultivation of a novel type of Common-cold virus in organ cultures. Br Med J 1(5448):1467-1470

Xi J, Longest PW (2007) Transport and deposition of micro-aerosols in realistic and simplified models of the oral airway. Ann Biomed Eng 35(4):560-81

Xi J, Longest PW (2008) Numerical predictions of submicrometer aerosol deposition in the nasal cavity using a novel drift flux approach. Int. J Heat Mass Transf 51(23-24):5562-5577

Yousefi M, Pourmehran O, Gorji-Bandpy M, Inthavong K, Yeo L, Tu J (2017) CFD simulation of aerosol delivery to a human lung via surface acoustic wave nebulization. Biomech Model Mechanobiol 16(6):2035-2050

Zhang H, Li D, Xie L, Xiao Y (2015) documentary research of human respiratory droplet characteristics. Proced Eng. https://doi. org/10.1016/j.proeng.2015.09.023

Publisher's Note Springer Nature remains neutral with regard to jurisdictional claims in published maps and institutional affiliations. 